\title{
Perancangan Penendang Bola pada Robot Beroda dengan Kelajuan Bola yang Dapat Diatur Menggunakan PWM
}

\author{
Andika Sukma Deryawan ${ }^{1}$, Fransiscus Dalu Setiaji ${ }^{2}$, Daniel Santoso ${ }^{3}$ \\ Program Studi Teknik Elektro, \\ Fakultas Teknik Elektronika dan Komputer, \\ Universitas Kristen Satya Wacana, Salatiga \\ 1andikasukma3@gmail.com, 2dalu.setiaji@staff.uksw.edu, \\ 33daniel.santoso@staff.uksw.edu
}

\begin{abstract}
Ringkasan
Dalam pertandingan sepakbola di mana pesertanya merupakan robot-robot beroda, dua tim saling mencari kemenangan berdasarkan jumlah gol terbanyak. Pada saat pertandingan berlangsung, keduanya saling berebut bola untuk menendang bola ke gawang lawan. Karena posisi robot terhadap gawang lawan tidak tetap, maka diperlukan sistem penendang bola yang dapat mengendalikan kekuatan tendang atau kelajuan awal bola saat ditendang. Pada makalah ini, diusulkan sebuah sistem penendang bola yang kekuatan tendangnya dapat divariasikan menggunakan PWM (Pulse Width Modulation). Sistem penendang bola ini menggunakan catu daya baterai. Energi dari baterai disimpan pada kapasitor yang nantinya digunakan untuk mencatu sebuah solenoida. Dengan mengatur nilai daur aktif (duty cycle) pulsa PWM dari 68,62\% sampai 100\%, maka sistem dapat menendang bola bermassa 0,4kg dengan kelajuan awal bervariasi antara $1,61 \mathrm{~m} / \mathrm{s}$ sampai $13,84 \mathrm{~m} / \mathrm{s}$.
\end{abstract}

Kata Kunci: robot sepak bola, penendang, kelajuan, bervariasi, PWM

\section{Pendahuluan}

Banyak kompetisi robot yang diadakan secara rutin di Indonesia. Salah satu di antaranya adalah KRI (Kontes Robot Indonesia) yang merupakan wadah bagi perguruan tinggi untuk menunjukkan teknologi robot terbaik yang dimiliki. Kelompok riset Robotic Research Center (R2C) dari Fakultas Teknik Elektronika dan Komputer, Universitas Kristen Satya Wacana (FTEK UKSW) juga ikut berpartisipasi dalam kontes tersebut.

Pada tahun 2017 dibentuk cabang baru dalam KRI yaitu Kontes Robot Sepak Bola Indonesia (KRSBI). Cabang ini mempertandingkan dua tim robot beroda yang bermain sepak bola. Terdapat maksimal tiga robot dalam setiap tim dan penentuan pemenang didasarkan atas jumlah gol terbanyak [1].

Gol terjadi saat robot berhasil menendang bola dan memasukkannya ke gawang lawan. Dalam pertandingan, robot tidak mengetahui dengan pasti kapan akan mendapatkan bola yang siap ditendang. Jika robot memiliki kemampuan untuk memvariasikan kekuatan tendangan bola atau kelajuan awal bola, maka robot akan dapat membuat gol dari berbagai posisi di lapangan sehingga lebih berpeluang memenangkan pertandingan. 
Makalah ini merupakan pengembangan dari [2] dimana pada makalah itu pengaturan kekuatan tendang dilakukan secara manual sebelum lomba, menggunakan sebuah potensiometer. Karena posisi robot berubah-ubah sepanjang pertandingan maka pengaturan manual tersebut kurang efektif. Pada makalah ini diusulkan pengaturan menggunakan sinyal PWM (Pulse Width Modulation) yang dapat dihasilkan oleh mikrokontoler atau prosesor lain yang nantinya akan mendapatkan masukan tentang posisi robot dari sensor tertentu seperti kamera. Dengan demikian setiap saat posisi robot dapat diprediksi dan kekuatan tendang dapat disesuaikan secara otomatis dengan mengatur nilai daur aktif (duty cycle) sinyal PWM.

\section{Perancangan}

Sistem penendang bola pada makalah ini menggunakan sebuah solenoida yang diberi tegangan tinggi untuk menghasilkan arus besar. Arus tersebut akan menghasilkan medan magnet yang dapat mendorong suatu besi plunger yang selanjutnya menggerakkan lengan ayun. Pergerakan lengan ayun inilah yang digunakan sebagai mekanisme penendang bola. Diagram kotak keseluruhan sistem penendang bola ditunjukkan pada Gambar 1.

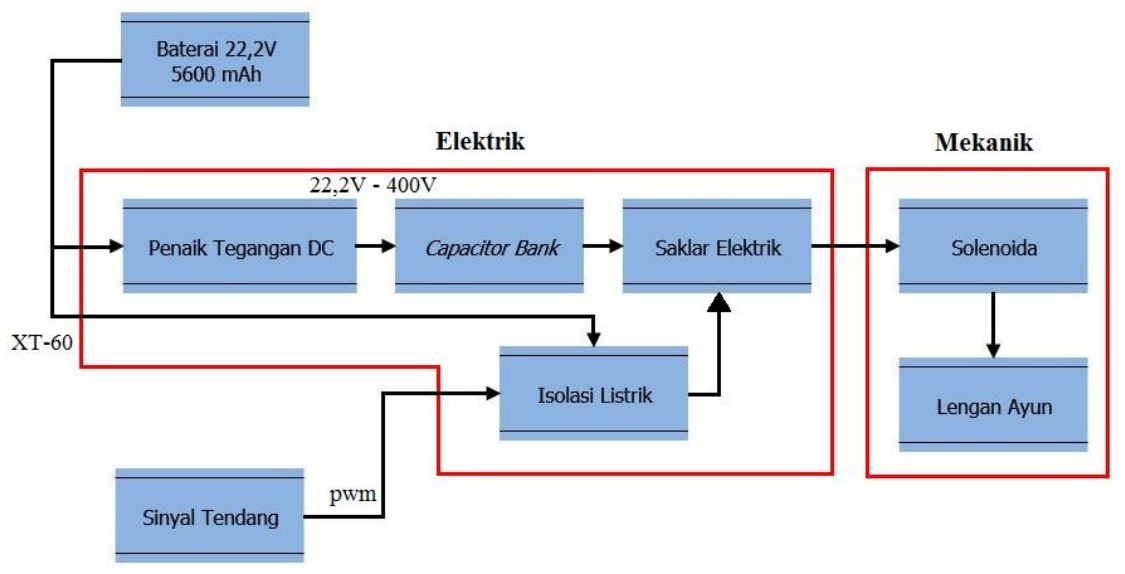

Gambar 1. Diagram kotak sistem elektrik penendang bola

\subsection{Penaik Tegangan DC}

Rangkaian Penaik Tegangan DC merupakan suatu Boost Converter yaitu rangkaian elektronik untuk menaikkan tegangan masukan dengan bantuan transistor yang difungsikan sebagai saklar [3]. Sumber tegangan masukan berasal dari baterai LiPo $5200 \mathrm{mAh}$ dengan tegangan saat terisi penuh 22,2V. Tegangan tinggi yang dihasilkan Boost Converter nantinya akan disimpan sementara pada sebuah kapasitor (Capacitor Bank) sebelum diberikan ke solenoida secara terkendali PWM. Boost Converter dibuat dengan menggunakan dua rangkaian seperti Gambar 2 yang dihubungkan secara paralel. Arus puncak total induktor ditetapkan $5 \mathrm{~A}$, sehingga masing-masing induktor, $L=1 \mathrm{mH}$, dialiri arus puncak 2,5A yang masih di bawah batas maksimal arus yang boleh melewatinya.

Untuk menentukan frekuensi pensaklaran induktor digunakan Persamaan (1).

$$
i_{\mathrm{L}}(t)=\frac{V_{\mathrm{i}}}{R_{\mathrm{DS}}(o n)+R_{\mathrm{I}}}\left(1-e^{\frac{-\left\{R_{\mathrm{DS}}(o n)+R\right\} t}{L}}\right)
$$

$i_{\mathrm{L}}=\operatorname{arus}$ induktor $(\mathrm{A})$ 
$\operatorname{RDS}($ on $)=$ tegangan drain-source saat MOSFET triode $(\Omega)$

$R_{\mathrm{I}}=$ hambatan dalam induktor $(\Omega)$

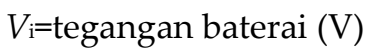

$L=$ nilai induktans $(\mathrm{H})$

Untuk menentukan karakteristik rangkaian Astable 555 yang dibutuhkan, maka terlebih dulu perlu dihitung nilai Ton yaitu saat keluaran Astable bernilai tinggi (high). Dengan memasukkan $t=T_{\mathrm{ON}}, i_{\mathrm{L}}\left(T_{\mathrm{ON}}\right)=2,5 \mathrm{~A}, R_{\mathrm{DS}}($ on $)=0,766 \Omega[4], R_{\mathrm{I}}=0,27 \Omega, V_{\mathrm{i}}=20 \mathrm{~V}$ (nilai $22,2 \mathrm{~V}$ hanya saat baterai penuh), $L=1 \mathrm{mH}$ maka didapatkan $T_{\mathrm{ON}}=100 \mu \mathrm{s}$. Dengan daur aktif (duty cycle) ditetapkan $60 \%$ maka $T_{\mathrm{OFF}}=67 \mu$ dan periode Astabe $T=T_{\mathrm{ON}}+T_{\mathrm{OFF}}=167 \mu \mathrm{s}$, atau frekuensi Astable $f=1 / T=6 \mathrm{kHz}$, yang direalisasiken menggunakan rangkaian seperti ditunjukkan Gambar 3.

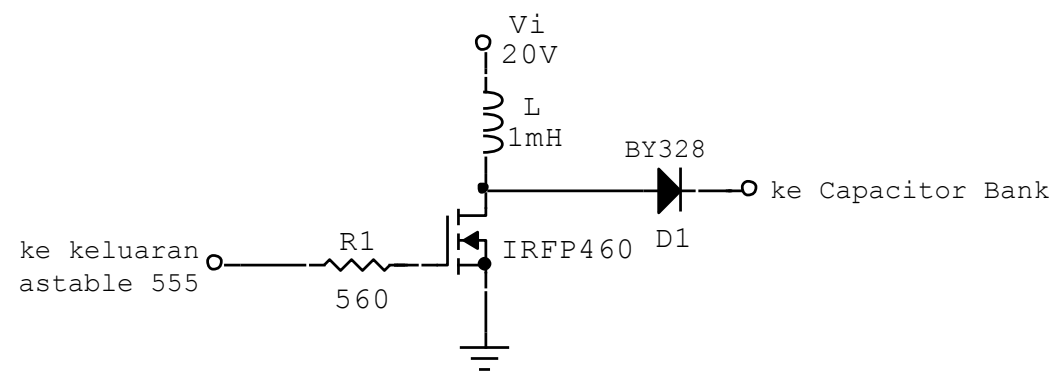

Gambar 2. Rangkaian Penaik Tegangan DC

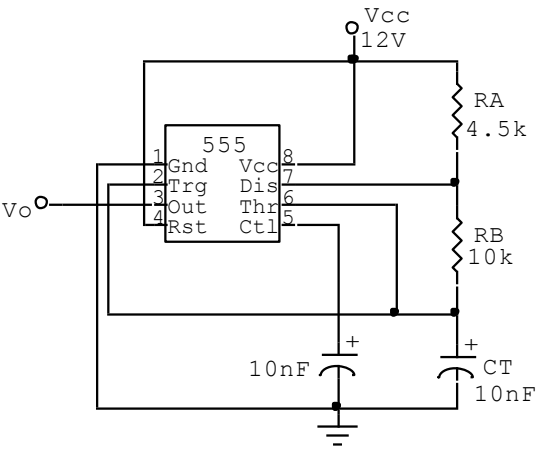

Gambar 3. Rangkaian Astable 555

\subsection{Capacitor Bank}

Tegangan baterai dinaikkan nilainya dan disimpan pada Capacitor Bank $\left(C_{\mathrm{B}}\right)$. Energi yang tersimpan nantinya digunakan mencatu sebuah solenoida sebagai bagian dari mekanisme penendang sebuah bola yang berdiameter $20 \mathrm{~cm}$ dan bermassa $0,4 \mathrm{~kg}$ dengan target kelajuan $9 \mathrm{~m} / \mathrm{s}$. Untuk menghitung energi minimal yang dibutuhkan digunakan Persamaan (2) dan didapatkan $E_{\min }=16,2 \mathrm{~J}$.

$$
E_{\min }=\frac{1}{2} m v^{2}
$$

$E_{\min }=$ energi minimal yang dibutuhkan $(\mathrm{J})$

$m=$ massa bola $(\mathrm{kg})$

$v=$ kelajuan bola $(\mathrm{m} / \mathrm{s})$ 
Dengan mengacu Persamaan (3), maka energi yang dibutuhkan untuk menggerakkan bola 0,4kg dengan kelajuan awal $9 \mathrm{~m} / \mathrm{s}$ adalah $16,2 \mathrm{~J}$. Karena konversi energi dari listrik ke mekanik bisa serendah 5\% [5] maka energi minimal yang dibutuhkan adalah $20 E_{\min }=324 \mathrm{~J}$. Capacitor Bank yang akan dipakai memiliki tegangan dadal 450V maka dipilih tegangan maksimal sebesar $400 \mathrm{~V}$, sehingga nilai minimal $C_{B}$ adalah:

$$
C_{\mathrm{B}}=\frac{2 \times 324}{400^{2}}=4000 \mu \mathrm{F}
$$

Perhitungan tersebut dilakukan dengan menganggap bola hanya bergerak linear. Jika bola juga berotasi maka dibutuhkan energi yang lebih tinggi, dengan kata lain nilai $C_{B}$ harus lebih besar. Maka dari itu pada makalah ini digunakan $C_{B}$ lebih besar dari perhitungan di atas, yaitu $4700 \mu \mathrm{F} / 450 \mathrm{~V}$.

\subsection{Saklar Elektrik}

Dengan nilai tegangan tinggi sebesar 400V maka saklar mekanik dihindari karena dapat menimbulkan percikan api saat peralihan kondisi. Pada makalah ini digunakan saklar elektrik menggunakan IGBT atau Insulated Gate Bipolar Transistor yang dapat dikendalikan waktu pensaklarannya sesuai rangkaian Gambar 4.

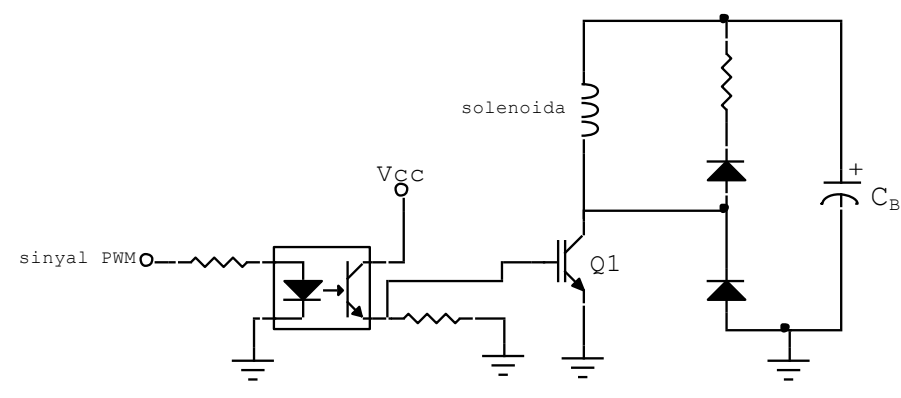

Gambar 4. Rangkaian saklar elektrik IGBT

Dengan sinyal masukan berupa PWM maka nilai rerata arus yang mengalir pada solenoida dapat diatur dengan melalui nilai daur aktif PWM (antara 0 sampai 100\%). Semakin besar nilai daur aktif maka nilai arus pada solenoida makin besar, medan magnet yang dihasilkan juga makin besar demikian pula kekuatan tendang pada bola. Berapa nilai daur aktif yang tepat tergantung pada masukan dari hasil perhitungan jarak antara robot ke gawang lawan (bukan merupakan bagian makalah ini).

\subsection{Solenoida}

Solenoida yang digunakan pada makalah ini adalah serupa dengan [2]. Spesifikasi dari solenoida ditunjukkan pada Tabel 1 dan bentuk dari solenoida ditunjukkan pada Gambar 5.

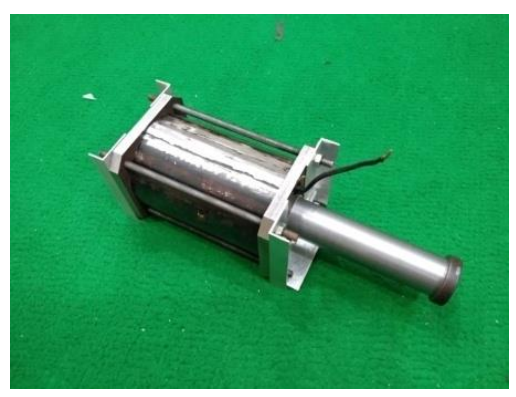

Gambar 5. Wujud fisik solenoida 
Tabel 1. Spesifikasi solenoida

\begin{tabular}{|c|c|}
\hline Parameter & Nilai \\
\hline Panjang Solenoida & $11,5 \mathrm{~cm}$ \\
\hline Lebar Solenoida & $3,1 \mathrm{~cm}$ \\
\hline Tinggi Solenoida & $6,6 \mathrm{~cm}$ \\
\hline Panjang Plunger & $26 \mathrm{~cm}$ \\
\hline Diameter Plunger & $3 \mathrm{~cm}$ \\
\hline Bahan Plunger & Besi dan Nylon \\
\hline Diameter Kawat & $0,8 \mathrm{~mm}$ \\
\hline Jumlah Layer & 12 \\
\hline Jumlah Lilitan & 1555 \\
\hline Nilai Resistansi & $7,4 \Omega$ \\
\hline $\begin{array}{c}\text { Ketebalan } \\
\text { Shielding }\end{array}$ & $1 \mathrm{~mm}$ \\
\hline Bahan Shielding & Besi \\
\hline
\end{tabular}

\subsection{Lengan Ayun}

Pada makalah ini solenoida yang digunakan untuk menendang ditempatkan di atas tiga buah motor DC yang tersambung dengan Planetary Gear $45 \mathrm{~mm}$ untuk menggerakkan robot. Peletakan solenoida pada robot adalah sama dengan pada [2].

Untuk menggerakkan bola dengan lintasan lambung, ditambahkan lengan ayun pada sisi depan solenoida. Lengan ayun terbuat dari bahan besi yang memiliki ketebalan $8 \mathrm{~mm}$. Desain mekanik lengan ayun ditunjukkan pada Gambar 6. Pada ujung lengan ayun ditambahkan karet berpegas untuk mengembalikan lengan ayun ke posisi awal setelah menendang bola.

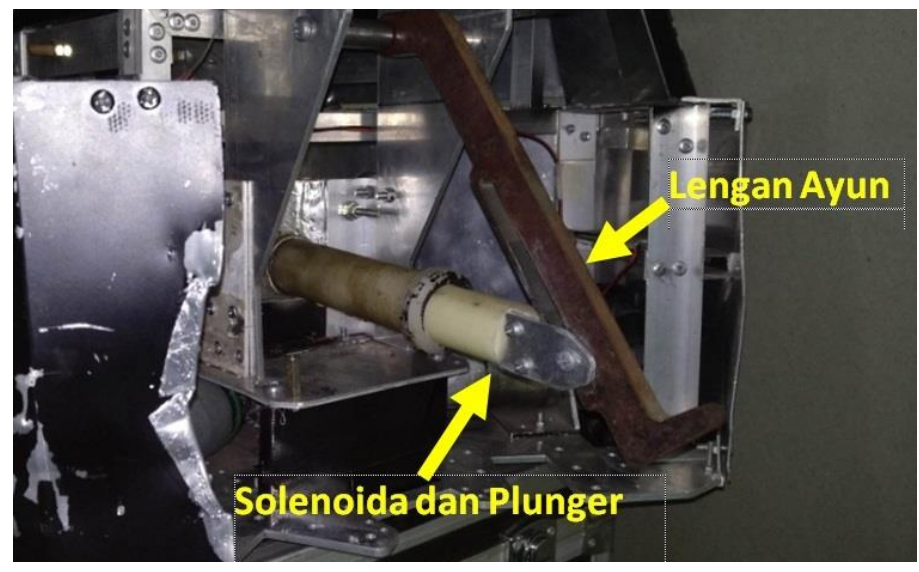

Gambar 6. Penempatan lengan ayun pada robot

\section{Pengujian}

\subsection{Pengujian Rangkaian Penaik Tegangan DC}

Pada pengujian ini, diukur waktu yang dibutuhkan oleh Penaik Tegangan DC untuk menaikkan tegangan kapasitor $C_{в}$ dari $0 \mathrm{~V}$ ke suatu nilai tegangan tertentu. Hasilnya ditunjukkan pada Tabel 2. Laju pengisian tegangan kapasitor melambat sesuai dengan karakteristik pengisian kapasitor yang bersifat non linear (eksponensial).

\subsection{Pengujian Kelajuan Bola}

Pada pengujian kelajuan bola yang ditendang, digunakan dua kondisi. Kondisi pertama adalah dengan membatasi nilai tegangan yang tersimpan pada $C_{в}$ agar diketahui 
hubungan antara kelajuan bola dengan tegangan pada Св. Pengujian kedua adalah dengan memberikan sinyal PWM dengan daur aktif yang divariasikan untuk mengetahui hubungannya dengan kelajuan bola.

Untuk menghitung kelajuan bola digunakan infrared obstacle detection dengan memanfaatkan interupsi pada mikrokontroler Arduino, seperti ditunjukkan Gambar 7.

Infrared obstacle detection menggunakan dua buah sensor cahaya inframerah. Saat benda mengenai Sensor Inframerah 1, sistem akan mulai menghitung waktu, dan saat benda mengenai Sensor Inframerah 2 waktu hitung dihentikan. Dengan mengetahui jarak kedua sensor inframerah $(50 \mathrm{~cm})$ dan selang waktu yang dibutuhkan bola untuk menempuh jarak tersebut, maka kelajuan bola dapat dihitung.

Tabel 2. Waktu pengisian Capacitor Bank, Св

\begin{tabular}{|c|c|c|}
\hline Tegangan Awal (V) & Tegangan Akhir (V) & Waktu (s) \\
\hline 0 & 50 & 0,2 \\
\hline 0 & 100 & 0,92 \\
\hline 0 & 150 & 3,12 \\
\hline 0 & 200 & 6,23 \\
\hline 0 & 250 & 11,92 \\
\hline 0 & 300 & 17 \\
\hline 0 & 350 & 24,95 \\
\hline 0 & 400 & 33,96 \\
\hline
\end{tabular}

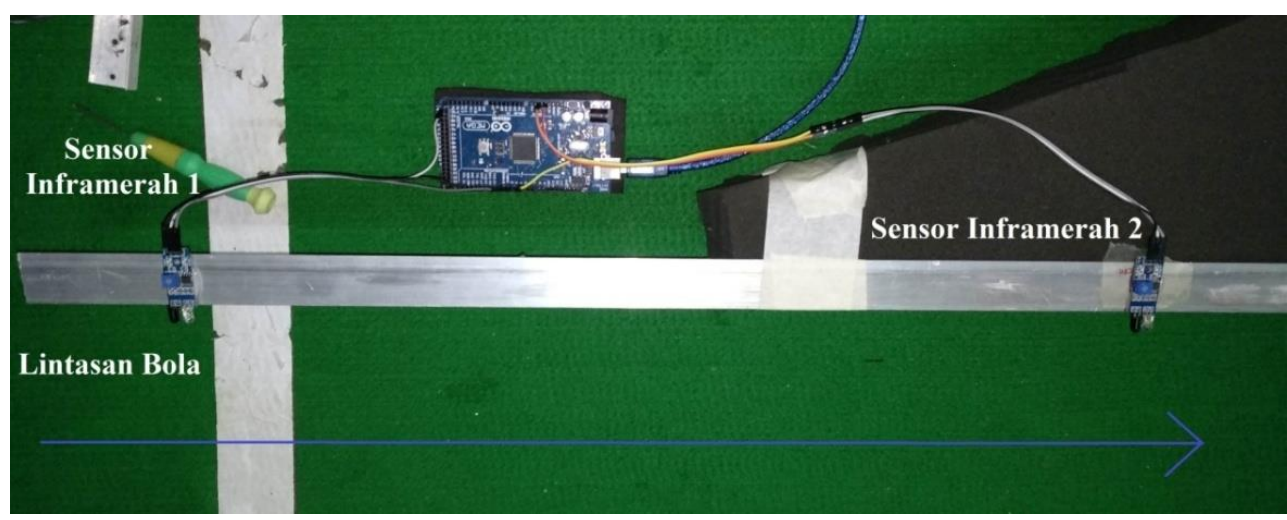

Gambar 7. Infrared obstacle detection untuk mengukur kelajuan bola

\subsubsection{Kelajuan Bola Sebagai Fungsi Tegangan Capacitor Bank}

Pada pengujian ini, penaik tegangan DC diatur tegangan keluarannya pada nilai tertentu untuk mencatu solenoida. Tegangan maksimal yang digunakan untuk mengisi kapasitor adalah 400V. Tabel 3 menunjukkan hasil pengukuran kelajuan bola, serta efisiensi konversi energi dari listrik ke mekanik dihitung menggunakan Persamaan (4).

Tabel 3. Kelajuan bola terhadap tegangan Capacitor Bank $\left(C_{B}\right)$

\begin{tabular}{|c|c|c|c|c|}
\hline$V_{\text {Св }}(\mathrm{V})$ & Energi pada Св $(\mathrm{J})$ & $v(\mathrm{~m} / \mathrm{s})$ & Energi Bola $(\mathrm{J})$ & $\eta(\%)$ \\
\hline 50 & 5,87 & 0,44 & 0,07 & $1,10 \%$ \\
\hline 100 & 23,5 & 2,82 & 2,65 & $11,29 \%$ \\
\hline 150 & 52,87 & 4,25 & 6,03 & $11,40 \%$ \\
\hline 200 & 94 & 5,86 & 11,44 & $12,16 \%$ \\
\hline 250 & 146,87 & 8,29 & 22,9 & $15,60 \%$ \\
\hline 300 & 211,5 & 11,18 & 41,65 & $19,69 \%$ \\
\hline 350 & 287,87 & 12,43 & 51,53 & $17,89 \%$ \\
\hline 400 & 376 & 13,84 & 63,8 & $16,96 \%$ \\
\hline
\end{tabular}




$$
\eta=\frac{0,5 m v^{2}}{0,5 C_{\mathrm{B}} \mathrm{V}_{\mathrm{CB}}^{2}} \times 100 \%
$$

Semakin tinggi tegangan yang tersimpan pada capacitor bank, maka semakin tinggi pula energi untuk mencatu solenoida sehingga membuat bola yang ditendang memiliki kelajuan yang lebih tinggi.

\subsubsection{Kelajuan Bola Sebagai Fungsi Daur Aktif PWM}

Untuk menghasilkan sinyal PWM digunakan mikrokontroler Arduino Mega2560 yang sudah memiliki fitur PWM[6]. Pada pengujian ini, kondisi sinyal PWM yaitu high selama $T_{\mathrm{H}}$ dan low selama $T_{\mathrm{L}}$, masing-masing dimanfaatkan untuk membuat IGBT on atau off. Daur aktif $(D)$ didefinisikan menurut Persamaan (5).

$$
D=\frac{T_{\mathrm{H}}}{T_{\mathrm{L}}+T_{\mathrm{H}}} \times 100 \%
$$

Tabel 4 menunjukkan hasil pengujian kelajuan bola dengan nilai $D$ yang divariasikan. Tabel 4 menunjukkan bahwa bola baru mulai bergerak untuk nilai $D \geq 68 \%$. Hal ini dikarenakan untuk $D$ yang rendah, gaya magnet yang dihasilkan solenoida belum dapat mengatasi gaya gesek mekanik yang terjadi dan kelembaman bola. Kelajuan bola meningkat seiring naiknya nilai $D$ karena arus rata-rata solenoid juga meningkat demikian pula besar gaya magnet yang digunakan untuk mendorong plunger sebagai penendang bola.

Tabel 4. Kelajuan bola sebagai fungsi nilai daur aktif PWM

\begin{tabular}{|c|c|}
\hline Daur Aktif PWM (\%) & Kelajuan Bola (m/s) \\
\hline 9,8 & 0 \\
\hline 19,6 & 0 \\
\hline 29,41 & 0 \\
\hline 39,21 & 0 \\
\hline 49,01 & 0 \\
\hline 58,82 & 0 \\
\hline 68,62 & 1,61 \\
\hline 78,43 & 6,65 \\
\hline 88,23 & 10,46 \\
\hline 98,03 & 12,3 \\
\hline 100 & 13,84 \\
\hline
\end{tabular}

\subsubsection{Pengujian Tendangan Lambung}

Pengujian dilakukan menggunakan penendang bola dengan lengan ayun seperti ditunjukkan Gambar 6. Untuk memperkirakan jarak bola dari titik awal ( $\mathrm{xH}$ ) digunakan digunakan Persamaan 6 [7] yang merupakan rumus untuk gerak proyektil suatu titik massa. Dimana $v=$ kelajuan awal, $\theta=18,5^{\circ}$ adalah sudut lengan ayun saat diaktifkan solenoida dan $g=9,8 \mathrm{~m} / \mathrm{s}^{2}$ adalah percepatan gravitasi bumi.

$$
x_{\mathrm{H}}=\frac{v^{2} \sin (2 \theta)}{g}
$$

Pada pengujian ini nilai $D$ divariasikan mulai dengan nilai $D$ yang memberikan jarak tendang bola yang signifikan, dengan hasil pengukuran ditunjukkan Tabel 5. Galat dalam tabel dihitung dengan membandingkan jarak tendang bola hasil perhitungan Persamaan (6), dengan jarak tendang yang terukur. 
Tabel 5. Pengujian tendangan lambung

\begin{tabular}{|c|c|c|c|}
\hline$D(\%)$ & Jarak Pengujian $(\mathrm{m})$ & Jarak Perhitungan $(\mathrm{m})$ & Galat $(\%)$ \\
\hline 68,62 & 0,33 & 0,16 & $-111,54$ \\
\hline 78,43 & 2,7 & 2,66 & $-1,45$ \\
\hline 88,23 & 7,83 & 6,58 & $-18,91$ \\
\hline 98,03 & 8,36 & 9,1 & 8,18 \\
\hline 100 & 8,6 & 11,47 & 25,07 \\
\hline
\end{tabular}

Pada saat $D=68,62 \%$ galat sangat besar karena pada saat bola mulai bergerak, energi redaman masih dominan dibandingkan energi yang diterima bola dari plunger solenoida. Untuk $D \geq 68,62 \%$ galat masih bisa mencapai 25\%, hal ini dikarenakan Persamaan(6) merupakan persamaan dengan berbagai asumsi ideal diantaranya tidak ada gesekan bola dengan udara serta massa, yang sulit dipenuhi dalam pengujian ini.

\section{Kesimpulan}

Berdasarkan perancangan, realisasi dan pengujian sistem yang dibuat, dapat disimpulkan beberapa hal sebagai berikut ini.

1. Sistem penaik tegangan berjenis Boost Converter yang dibuat membutuhkan waktu sekitar 34s untuk menaikkan tegangan Capacitor Bank berkapasitas $4700 \mu \mathrm{F}$ dari tegangan 0V hingga 400V.

2. Sistem penendang bola dapat menggerakkan bola bermasa $0,4 \mathrm{~kg}$ dengan diameter $20 \mathrm{~cm}$ dengan kelajuan maksimal 13,84 m/s saat Capacitor Bank bertegangan $400 \mathrm{~V}$.

3. Efisiensi konversi energi listrik menjadi energi gerak bola mencapai $19,69 \%$ pada saat Capacitor Bank bertegangan $300 \mathrm{~V}$.

4. Sistem penendang bola dapat mengendalikan kekuatan tendang dengan mengatur nilai daur aktif sinyal PWM dengan nilai minimal 68,62 \% agar bola mulai bergerak.

5. Dengan menerapkan rumus gerak parabolik proyektil (bola dianggap suatu titik massa), maka pengukuran jarak jatuh bola memiliki galat maksimal $112 \%$ (untuk $D=68,62 \%$ ), dan minimal $-1,45 \%$ (untuk $D=78,43 \%$ ), jika dibandingkan dengan hasil perhitungan rumus tersebut.

\section{Daftar Pustaka}

[1] Direktoral Jenderal Pembelajaran dan Kemahasiswaan, Buku Panduan Kontes Robot Sepakbola Divisi Beroda, Jakarta, Indonesia: Kementerian Riset, Teknologi dan Perguruan Tinggi, 2018.

[2] Y Haryudanta, F Dalu Setiaji, Gunawan Dewantoro, Rancang Bangun Mekanisme Penendang Bola Berbasis Elektromagnetik untuk Robot Sepakbola Beroda R2C-Warrior, Techne Jurnal Ilmiah Elektroteknika, Vol. 17, No. 1, April 2018

[3] Texas Instruments Incorporated, Understanding Boost Power Stages in Switchmode Power Supplies, 1999.

[4] Vishay Siliconix, IRFP460, Juli 2008.

[5] M.S Serafim, Ball Handling Mechanism for Mobile Robots, Tecnico Lisboa, Thesis 2013.

[6] Massimo Banzi, Getting Started with Arduino, 5th ed., Sebastopol, USA: an imprint of Maker Media, a division of O'Reilly Media, Inc, 2009.

[7] João Silva, José Luis Azeved, Bernardo Cunha, António J. R. Neves, Nuno Lau Ricardo Dias, Improving the Kicking Accuracy in a Soccer Robot, ACM, vol. 4, p. 15, April 2015. 